Jurnal Media Agribisnis Vol. 4 No. 1 Tahun 2019 Hal 21 - 27

Media Komunikasi Hasil Penelitian Bidang Ilmu Agribisnis

ISSN print 2548-7027

ISSN online 2541-6898

\title{
HUBUNGAN MOTIVASI KERJA DENGAN KINERJA KARYAWAN PADA PT KUMPEH KARYA LESTARI DI DESA SAKEAN KECAMATAN KUMPEH ULU KABUPATEN MUARO JAMBI
}

\author{
1)*Asmaida, ${ }^{1)}$ Wiwin Alawiyah, dan ${ }^{2)}$ Ilvan Agandhitra \\ ${ }^{1)}$ Program Studi Agribisnis, Fakultas Pertanian Universitas Batanghari \\ ${ }^{2)}$ Alumni Program Studi Agribisnis, Fakultas Pertanian Universitas Batanghari \\ Jl. Slamet Riyadi-Broni, Jambi. 36122. Telp. +6274160103 \\ 1)*Email korespondensi : asmaida.syandri@yahoo.co.id
}

\begin{abstract}
This study aims were to describe the employees motivation and describe the employees performance in this company and also to analyzing the relationship between work motivation and employee performance in wood processing of plywood at PT Kumpeh Karya Lestari in Sakean Village, Kumpeh Ulu District, Muaro Jambi Regency.Data was analized by descriptive (qualitative-quantitative) and inferency analysis. To describe the work motivation and performance of employees was knowed by descriptive analysis, furthermore to analysis relations between analysis and performance of employees using the non-parametric statistical analysis called Chi Square Test.The results of this study showed that 1). The employees work motivation was high. 2). Employee performance in PT Kumpeh Karya Lestari had a positively categorized and 3). There was strong level of relationship between work motivation and employee performance in PT Kumpeh Karya Lestari in Sakean Village, Kumpeh Ulu District, Muaro Jambi Regency.

Keywords: Motivation, Performance, PT. Kumpeh Karya Lestari
\end{abstract}

\begin{abstract}
Abstrak
Penelitian ini bertujuan untuk mendeskripsikan motivasi kerja karyawan dan kinerja karyawan serta menganalisis hubungan antara motivasi kerja dengan kinerja dalam pengolahan kayu menjadi kayu lapis di PT Kumpeh Karya Lestari Di Desa Sakean Kecamatan Kumpeh Ulu Kabupaten Muaro Jambi. Data penelitian dianalisis menggunakan metode deskriptif kualitatif-kuantitatif dan interperensi. Uengetahui gambaran motivasi kerja dan kinerja karyawan dianalisis secara deskriptif, sedangkan melihat hubungan motivasi kerja dan kinerja karyawan dalam pengolahan kayu lapis dianalisis secara kuantitatif dengan menggunakan analisis statistik non parametrik Uji Chi Square. Hasil penelitian menunjukan bahwa 1). Motivasi kerja karyawan di PT Kumpeh Karya Lestari adalah berkatergori tinggi, 2). Kinerja karyawan pada PT Kumpeh Karya Lestari berkategori positif, dan 3). Terdapat hubungan antara motivasi kerja dan kinerja karyawan pada PT Kumpeh Karya Lestari Di Desa Sakean Kecamatan Kumpeh Ulu Kabupaten Muaro Jambi, dengan tingkat keeratan hubungan kuat.

Kata kunci : Motivasi, Kinerja, PT. Kumpeh Karya Lestari
\end{abstract}

Diterbitkan oleh Program Studi Agribisnis Fakultas Pertanian Universitas Batanghari Jambi Halaman 21 
Jurnal Media Agribisnis Vol. 4 No. 1 Tahun 2019 Hal 21 - 27

Media Komunikasi Hasil Penelitian Bidang Ilmu Agribisnis

ISSN print 2548-7027

ISSN online 2541-6898

\section{PENDAHULUAN}

Sumber daya manusia memiliki peranan penting dalam setiap kegiatan dari sebuah perusahaan, di karena kan sumber daya manusia dalam suatu perusahaan memiliki fungsi sebagai pelaksana dan juga memiliki potensi yang besar untuk menjalankan aktivitas perusahaan, potensi dari sumber daya manusia yang ada harus dimanfaatkan dengan sebaik-baiknya agar memperoleh hasil yang maksimal, serta bagaimana pun juga kemajuan dan keberhasilan dari suatu perusahaan tidak lepas dari peran sumber daya manusia yang baik (Ira Rahmadita, 2013) .

Penggunaan tenaga kerja yang efektif merupakan kunci keberhasilan perusahaan, untuk itu dibutuhkan kebijakan dalam menggunakan tenaga kerja agar mau bekerja lebih produktif sesuai dengan rencana yang telah ditetapkan. Salah satu faktor pendukung yang dapat menentukan hasil kerja yaitu terkait dengan kondisi atau lingkungan kerja yang mampu mendukung segala aktivitas perusahaan. Pihak manajemen mempunyai kaitan yang erat dengan upaya untuk memaksimalkan potensi yang dimiliki sumber daya perusahaan, sebab keberhasilan manajemen dalam menggerakkan karyawan dalam mencapai tujuan yang telah ditetapkan sangat tergantung pada pengetahuan pimpinan atau pihak manajemen yang salah satunya yaitu mengenai kondisi lingkungan kerja dimana karyawan bekerja. Kondisi lingkungan kerja tersebut mencakup mengenai lokasi luar gedung sampai jumlah pencahayaan dan suara yang menimpa meja kerja atau ruang kerja seorang tenaga kerja (Munandar, 2001).

PT Kumpeh Karya Lestari Di Desa Sakean Kecamatan Kumpeh Ulu Kabupaten Muaro Jambi adalah salah satu perusahan agribisnis yang bergerak dalam pengolahan kayu menjadi kayu lapis. PT Kumpeh Karya Lestari sudah berdiri dari tahun 1996 dan memproduksi kayu lapis dengan 3 type yaitu type UT, Reject, dan Afkir.PT Kumpeh Karya Lestari sendiri mempunyai karyawan kurang lebih seratus karyawan yang bekerja diberbagai bidang mulai dari bekerja di rotari, glue, hot press, cool press, boiler, pengampalasan dan packing. Banyaknya karyawan yang bekerja diperusahaan tersebut tentunya akan sangat berpengaruh kepada produksi yang akan dihasilkan oleh perusahaan jika dibarengi dengan pengalokasian tenaga kerja yang efektif dan terorganisir.

Hasil produksi dari kerja perusahaan tentu dipengaruhi oleh motivasi kerja karyawan yang tinggi atau rendah. Tingginya motivasi karyawan akan berdampak positif terhadap berjalannya kegiatan perusahaan. Kinerja karyawan dapat ditunjukkan dengan hasil kerjanya (output), apakah karyawan tersebut mempunyai kinerja yang tinggi atau rendah. Output yang rendah dapat dikatakan sebagai akibat karena kinerja karyawan yang menurun atau sebaliknya. Naik turunnya produksi dari perusahaan tentu salah satu dipengaruhi oleh kinerja karyawan dan kinerja karyawan dipengaruhi oleh motivasi dari dalam diri para karyawan. Berdasarkan uraian tersebut, penulis tertarik meneliti "Hubungan Motivasi Kerja Dengan Kinerja Karyawan Pada PT Kumpeh Karya Lestari Di Desa Sakean Kecamatan Kumpeh Ulu Kabupaten Muaro Jambi”,dengan tujuan :

1. Mendeskripsikan motivasi kerja karyawan dalam pengolahan kayu menjadi kayu lapis di PT Kumpeh Karya Lestari Di Desa Sakean Kecamatan Kumpeh Ulu Kabupaten Muaro Jambi. 
Jurnal Media Agribisnis Vol. 4 No. 1 Tahun 2019 Hal 21 - 27

Media Komunikasi Hasil Penelitian Bidang Ilmu Agribisnis

ISSN print 2548-7027

ISSN online 2541-6898

2. Mendeskripsikan kinerja karyawan dalam pengolahan kayu menjadi kayu lapis di PT Kumpeh Karya Lestari Di Desa Sakean Kecamatan Kumpeh Ulu Kabupaten Muaro Jambi.

3. Menganalisis hubungan antara motivasi kerja dengan kinerja karyawan dalam pengolahan kayu menjadi kayu lapis di PT Kumpeh Karya Lestari Di Desa Sakean Kecamatan Kumpeh Ulu Kabupaten Muaro Jambi.

\section{METODOLOGI PENELITIAN}

Penelitian ini dilaksanakan di PT Kumpeh Karya Lestari Di Desa Sakean Kecamatan Kumpeh Ulu Kabupaten Muaro Jambi, yang ditentukan secara Purposive (sengaja). Metode penelitian menggunakan metode survei. Menurut Silalahi,U. 2010, survei adalah suatu usaha untuk mendapatkan dan mengumpulkan data dan informasi dari berbagai sumber. Petani adalah sebagai sumber data primer, dengan tehnik pengumpulan data secara observasi dan wawancara dengan menggunakan kuisioner. Menurut Singarimbun dan Effendi (1995), wawancara adalah cara yang dilakukan untuk mendapatkan informasi dengan cara bertanya langsung kepada responden. Data sekunder adalah data yang diperoleh atau dikumpulkan oleh pihak lain, dapat bersumber dari pustaka dan lembaga yang terkait dengan penelitian ini. Jenis data yang dikumpulkan adalah jenis data cross section dengan skala ukur jenis data nominal.

Berdasarkan data PT. Kumpeh Karya Lestari Di Desa Sakean Kecamatan Kumpeh Ulu Kabupaten Muaro Jambi, PT. Kumpeh Karya Lestari memiliki total populasi atau karyawan berjumlah 105 orang. Menurut Winarno (1994) bila populasi cukup homogen, terhadap populasi dibawah 100 dapat digunakan sampel sebanyak $50 \%$, bila populasi di atas 100 dapat diambil sebesar $15 \%$. Berdasarkan pendapat Winarno tersebut, maka diambil sampel sebanyak 28\% (30 orang) yang dipilih dengan menggunakan metode simple random sampling, yang pelaksanaannya dilakukan secara undian.

Data penelitian dianalisis menggunakan metode deskriptif kualitatifkuantitatif dan interperensi untuk menjawab perumusan masalah, tentang gambaran motivasi kerja karyawan dan kinerja karyawan serta hubungan antara motivasi kerja dengan kinerja karyawan dalam pengolahan kayu menjadi kayu lapis di PT Kumpeh Karya Lestari Di Desa Sakean Kecamatan Kumpeh Ulu Kabupaten Muaro Jambi.

Analisis deskriptif digunakan untuk mengetahui gambaran motivasi kerja dan kinerja karyawan dalam pengolahan kayu lapis di PT Kumpeh Karya Lestari Di Desa Sakean Kecamatan Kumpeh Ulu Kabupaten Muaro Jambi. Selanjutnya untuk melihat hubungan motivasi kerja dan kinerja karyawan dalam pengolahan kayu lapis digunakan analisis dengan menggunakan statistik non parametrik Uji Chi Square dengan tabel kontingensi 2 x 2, menurut Sudjana (2002) dengan formulasi rumus sebagai berikut : 
Jurnal Media Agribisnis Vol. 4 No. 1 Tahun 2019 Hal 21 - 27

Media Komunikasi Hasil Penelitian Bidang Ilmu Agribisnis

ISSN print 2548-7027

ISSN online 2541-6898

$x^{2}=\frac{\mathrm{n}(\| \mathrm{ad}-\mathrm{bc}-1 / 2 \mathrm{n})^{2}}{(\mathrm{a}+\mathrm{b})(\mathrm{a}+\mathrm{c})(\mathrm{b}+\mathrm{d})(\mathrm{c}+\mathrm{d})}$

Dimana :

$\mathrm{n} \quad=$ sampel

a,b,c,d = komponen matrik pada tabel kontingensi

Adapun tabel penolong dalam analisis adalah seperti terlihat pada Tabel 1 berikut:

Tabel 1. Model Uji Chi Square dengan Kontingensi ( C ) 2x2

\begin{tabular}{cccc}
\hline Kotivasi & Positif & Negatif & Jumlah \\
\hline Tinggi & $\mathrm{a}$ & $\mathrm{b}$ & $\mathrm{a}+\mathrm{b}$ \\
Rendah & $\mathrm{c}$ & $\mathrm{d}$ & $\mathrm{c}+\mathrm{d}$ \\
\hline Jumlah & $\mathrm{a}+\mathrm{c}$ & $\mathrm{b}+\mathrm{d}$ & $\mathrm{n}$
\end{tabular}

Nilai pada Tabel $2 \times 2$ dengan derajat $(\mathrm{db})=1$ pada tingkat kepercayaan 95\% adalah 3,481 dengan ketentuan sebagai berikut :

Hipotesis Statistik :

$$
\begin{aligned}
& x^{2}=0 \\
& x^{2} \neq 0
\end{aligned}
$$

HipotesisOperasional :

$\mathrm{H}_{\mathrm{o}}=$ Tidak terdapat hubungan antara motivasi kerja dengan kinerja karyawan dalam pengolahan kayu lapis di PT. Kumpeh Karya Lestari Di Desa Sakean Kecamatan Kumpeh Ulu Kabupaten Muaro Jambi

$\mathrm{H}_{\mathrm{a}}=$ Terdapat hubungan antara motivasi kerja dengan kinerja karyawan di PT. Kumpeh Karya Lestari Di Desa Sakean Kecamatan Kumpeh Ulu Kabupaten Muaro Jambi.

Kaidah pengambilan keputusan adalah :

Jika $x_{\text {hitung }}^{2} \geq x_{\text {tabel }}^{2} ;(\alpha=5 \%$ dengan $\mathrm{db}=(\mathrm{m}-1)(\mathrm{n}-1))$ maka terima $\mathrm{H}_{\mathrm{a}}$

Jika $x^{2}$ hitung $<x^{2}$ tabel $;\left(\alpha=5 \%\right.$ dengan $\mathrm{db}=(\mathrm{m}-1)(\mathrm{n}-1)$ maka tolak $\mathrm{H}_{\mathrm{a}}$

Selanjutnya bila terlihat adanya hubungan antar dua variabel yang diteliti maka dilanjutkan dengan melihat keeratan hubungan tersebut dengan menggunakan Uji Kontingensi (taraf keeratan hubungan) dengan menggunakan rumus Coefisiensi Contingensi (CC) (J.Suprapto,1998) sebagai berikut :

$\mathrm{C}=\sqrt{\frac{\mathrm{x}^{2} \text { hit }}{\mathrm{n}+\mathrm{x}^{2} \text { hit }}}$

Dimana :

$X^{2}$ hit = Besarnya nilai Chi- Square hasil hitungan

$\mathrm{N} \quad=$ Jumlah sampel

$\mathrm{C} \quad=$ Koefisien Kontingensi atau derajat keeratan hubungan

Adapun kategori keeratan adalah sebagai berikut :

$\mathrm{C}=0-0.353 \quad$ (Menunjukkan hubungan yang lemah)

$\mathrm{C}=0.354-0,707 \quad$ (Menunjukkan hubungan yang kuat)

$\mathrm{C}=0.8-1 \quad$ (Menunjukkan hubungan yang sempurna)

Diterbitkan oleh Program Studi Agribisnis Fakultas Pertanian Universitas Batanghari Jambi Halaman 24 
Jurnal Media Agribisnis Vol. 4 No. 1 Tahun 2019 Hal 21 - 27

Media Komunikasi Hasil Penelitian Bidang Ilmu Agribisnis

ISSN print 2548-7027

ISSN online 2541-6898

\section{HASIL DAN PEMBAHASAN}

\section{Gambaran Motivasi Kerja Karyawan Pada PT Kumpeh Karya Lestari.}

Motivasi adalah sesuatu yang menimbulkan proses pemberian dorongan bekerja kepada karyawan sedemikian rupa sehingga dapat mau bekerja ikhlas demi tercapainya tujuan organisasi secara efisien. Motivasi yang baik diperusahaan akan diharapkan akan menghasilkan kinerja yang baik juga sehingga dapat memberi dampak ke dalam operasional perusahaan. Gambaran motivasi kerja karyawan pada PT Kumpeh Karya Lestari Di Desa Sakean Kecamatan Kumpeh Ulu Kabupaten Muaro Jambi dapat dilihat pada Tabel 2.

Tabel 2. Distribusi Frekuensi Karyawan Berdasarkan Motivasi Kerja Pada PT Kumpeh Karya Lestari.

\begin{tabular}{ccc}
\hline $\begin{array}{c}\text { Distribusi Kategori } \\
\text { Motivasi Kerja }\end{array}$ & Frekuensi (Orang) & Persentase (\%) \\
\hline Tinggi & 27 & 90 \\
Rendah & 3 & 10 \\
\hline Jumlah & 30 & 100 \\
\hline
\end{tabular}

Sumber : Data Primer diolah, Tahun 2019

Dari Tabel 2 dapat dilihat bahwa karyawan yang memiliki motivasi kerja tinggi sebesar 27 Orang (90 \%) sedangkan karyawan yang memiliki motivasi kerja rendah terdapat sebanyak 3 orang (10\%). Rata-rata karyawan di perusahaan PT Kumpeh Karya Lestari memiliki motivasi yang tinggi di dorong oleh keinginan memperoleh kompensasi, pujian dari atasan, ingin memperoleh promosi jabatan, ingin tetap bekerja di perusahaan, ingin memperoleh prestasi kerja, bertanggung jawab sebagai karyawan, ingin memperoleh pengalaman dari perusahaan, bekerja dengan SOP perusahaan, bekerja melebihi target dan bekerja bukan karna di suruh.

\section{Gambaran Kinerja Karyawan Pada PT Kumpeh Karya Lestari}

Kinerja adalah hasil kerja secara kualitas dan kuantitas yang dicapai oleh seorang dalam melaksanakan fungsinya sesuai dengan tanggung jawab yang diberikan kepadanya. Gambaran kinerja karyawan pada PT Kumpeh Karya Lestari Di Desa Sakean Kecamatan Kumpeh Ulu Kabupaten Muaro Jambi dapat dilihat pada Tabel 3.

Tabel 3. Distribusi Frekuensi Karyawan Berdasarkan Kinerja Pada PT Kumpeh Karya Lestari.

\begin{tabular}{ccc}
\hline $\begin{array}{c}\text { Distribusi Kategori } \\
\text { Kinerja }\end{array}$ & Frekuensi (Orang) & Persentase (\%) \\
\hline Positif & 26 & 86,67 \\
Negatif & 4 & 13,33 \\
\hline Jumlah & 30 & 100 \\
\hline
\end{tabular}

Sumber : Data Primer diolah, 2019 
Jurnal Media Agribisnis Vol. 4 No. 1 Tahun 2019 Hal 21 - 27

Media Komunikasi Hasil Penelitian Bidang Ilmu Agribisnis

ISSN print 2548-7027

ISSN online 2541-6898

Dari Tabel 3 di atas dapat dilihat bahwa Kinerja karyawan mayoritas positif yaitu sebanyak 26 Orang $(86,67 \%)$ dan kinerja yang negatif yaitu sebanyak 4 orang (13,33\%). Rata-rata karyawan di perusahaan PT Kumpeh Karya Lestari memiliki kinerja yang positif. Hal ini dapat dilihat dari kedisiplinan karyawan dalam hal bekerja untuk mencapai bahkan melebihi target yang di berikan, waktu kerja, mengikuti aturan dan perintah dari atasan, bersemangat dalam melakukan pekerjaan, tidak pernah menunda pekerjaan, melakukan pekerjaan sesuai SOP perusahaan, semua pekerjaan dengan baik, menerima resiko baik atau buruknya hasil pekerjaan, teliti melakukan pekerjaan.

\section{Hubungan Antara Motivasi Kerja dengan Kinerja Karyawan pada PT Kumpeh Karya Lestari.}

Motivasi kerja seseorang terhadap suatu pekerjaan diharapkan akan mempengaruhi kinerjanya diperusahaan tersebut. Motivasi kerja yang tinggi maupun rendah dalam melakukan segala kegiatan di dalam pekerjaannya sebagai karyawan di dalam suatu perusahaan akan menghasilkan kinerja yang sejalan juga dengan motivasinya. Ada beberapa hal yang termasuk ke dalam motivasi diantaranya ingin menafkahi keluarga, promosi jabatan, ingin memperoleh penghargaan dan pujian dari atasan dan banyak juga hal lain, diharapkan akan sejalan dengan menghasilkan kinerja yang sejalan juga dengan motivasinya. Untuk lebih jelasnya distribusi frekuensi hubungan antara motivasi kerja dan kinerja karyawan pada PT Kumpeh Karya Lestari Di Desa Sakean Kecamatan Kumpeh Ulu Kabupaten Muaro Jambi dapat dilihat pada Tabel 4.

Tabel 4. Distribusi Frekuensi Karyawan Berdasarkan Hubungan Motivasi Kerja dengan Kinerja Karyawan pada PT Kumpeh Karya Lestari

\begin{tabular}{ccccccc}
\hline \multirow{2}{*}{ Kategori } & \multicolumn{7}{c}{ Kategori Kinerja } \\
\cline { 2 - 5 } Motivasi & \multicolumn{2}{c}{ Positif } & \multicolumn{2}{c}{ Negatif } & Jumlah & Persentase \\
\cline { 2 - 5 } Kerja & Jumlah & Persentase & Jumlah & Persentase & (Orang) & $(\%)$ \\
& $($ Orang) & $(\%)$ & $($ Orang) & $(\%)$ & & \\
\hline Tinggi & 26 & 86,67 & 1 & 3,33 & 27 & 90,00 \\
Rendah & 0 & 0 & 3 & 10 & 3 & 10,00 \\
\hline Jumlah & 26 & 86,67 & 4 & 13,33 & 30 & 100 \\
\hline
\end{tabular}

Sumber : Data Primer diolah, Tahun 2019

Dari Tabel 4 di atas diketahui bahwa dari 30 orang karyawan menunjukan sebanyak 90,00\% yaitu 27 orang karyawan memiliki motivasi kerja tinggi dan $10 \%$ atau 3 orang memiliki motivasi kerja rendah. Dari 27 orang karyawan tersebut terdapat sebanyak 26 orang $(86,67 \%)$ adalah berkategori motivasi kerja tinggi dengan kinerja karyawan positif dan yang berkategori motivasi kerja tinggi dengan kinerja karyawan negatif sebanyak 1 orang $(3,33 \%)$. Selanjutnya dari 3 orang karyawan tersebut sebanyak 0 orang $(0 \%)$ adalah berkategori motivasi kerja rendah dengan kinerja karyawan positif dan yang berkategori motivasi kerja rendah dengan kinerja karyawan negatif sebanyak 3 orang (10\%).

Berdasarkan hasil perhitungan uji chi square hubungan antara motivasi kerja dan kinerja karyawan pada PT Kumpeh Karya Lestari pada Desa Sakean 
Jurnal Media Agribisnis Vol. 4 No. 1 Tahun 2019 Hal 21 - 27

Media Komunikasi Hasil Penelitian Bidang Ilmu Agribisnis

ISSN print 2548-7027

ISSN online 2541-6898

Kecamatan Kumpeh Ulu Kabupaten Muaro Jambi diperoleh nilai $x^{2}{ }_{\text {hitung }}$ sebesar 14,13. Nilai $x_{\text {2hitung }}$ tersebut lebih besar dari nilai $x^{2}$ tabel sebesar 3,481, di mana keputusannya adalah menolak Ho dan menerima Ha, artinya terdapat hubungan antara motivasi kerja dengan kinerja karyawan pada PT Kumpeh Karya Lestari Di Desa Sakean Kecamatan Kumpeh Ulu Kabupaten Muaro Jambi, dengan nilai taraf keeratan hubungan adalah sebesar 0,56 yang artinya keeratan hubungan menunjukkan hubungan yang kuat antara motivasi kerja dengan kinerja karyawan pada PT Kumpeh Karya Lestari Di Desa Sakean Kecamatan Kumpeh Ulu Kabupaten Muaro Jambi.

\section{KESIMPULAN}

Berdasarkan hasil penelitian dan pembahasan dapat ditarik kesimpulan sebagai berikut:

1. Motivasi kerja karyawan di PT Kumpeh Karya Lestari berkategori tinggi dalam hal memperoleh kompensasi, mendapatkan pujian, kesempatan promosi jabatan, tetap bekerja di perusahaan, tanggung jawab sebagai karyawan, pengalaman di perusahaan, SOP, melebihi target perusahaan, bekerja bukan karena di suruh atasan.

2. Kinerja karyawan pada PT Kumpeh Karya Lestari berkategori positif dalam hal kedisplinan, kinerja melebihi target perusahaan, datang tepat waktu, melakukan perintah, bersemangat melakukan pekerjaan, tidak menunda pekerjan, SOP, melakukan pekerjaan dengan baik, menerima resiko baik buruknya hasil pekerjaan, teliti melakukan pekerjaan.

3. Terdapat hubungan antara motivasi kerja dengan kinerja karyawanpadaPT Kumpeh Karya Lestari Di Desa Sakean Kecamatan Kumpeh Ulu Kabupaten Muaro Jambi, dengan taraf keeratan hubungan yang kuat.

\section{DAFTAR PUSTAKA}

Handayani. 2003. Manajemen Pengembangan Sumber Daya Manusia. Penerbit: PT RajaGrafindo Persada. Jakarta

J Supranto. 1998. Metode Kuantitatif Teori dan Aplikasi Untuk Bisnis dan Ekonomi. AMP YPKM: Yogyakarta.

Munandar. 2001. Psikologi industri dan Organisasi. Universitas Iindonesia. Depok

Rahmawati Ira. 2010. Pengaruh Motivasi Kerja Terhadap Kinerja Karyawan Pada PT Panasonic Gobel Indonesia. Skripsi IBM ASMI. Jakarta.

Sari Dewi T. 2010. Hubungan Antara Motivasi Dan Budaya Kerja Dengan Kinerja Penyuluh Pertanian Di Kabupaten Subang. Provinsi Jawa Barat

Singarimbun. Masri dan Sofian Efendi. 1989. Metode Penelitihan survery. LP3ES. Jakarta

Soekartawi. 2005. Agribisnis Teori dan Aplikasinya. Raja Grafindo Persada Jakarta

Sudjana. 2002 Metode Penelitian. Edisi revisi Jakarta Rineka Cipta.

Uno. 2003. Motivasi Kepemimpinan dan Efektivitas Kelompok. Penerbit Rineka Cipta. Jakarta.

Winarno S. 1994. Pengantar Penelitihan Ilmiah (dalam metode teknik). Kanisius. Bandung 